\title{
ABORDAGEM GEOAMBIENTAL APLICADA À ANÁLISE DA VULNERABILIDADE E DOS RISCOS EM AMBIENTES URBANOS
}

\author{
GEOENVIRONMENTAL APPROACH APPLIED TO EVALUATION OF \\ VULNERABILITY AND RISKS IN URBAN ENVIRONMENTS
}

\author{
APPROCHE GÉO-ENVIRONNEMENTALE APPLIQUÉE À L'ANALYSE DE LA \\ VULNÉRABILITÉ ET DES RISQUES EN MILIEU URBAIN \\ Jader de Oliveira Santos - Universidade Federal do Ceará - Fortaleza - Ceará - Brasil \\ jadersantos@ufc.br
}

Marcos José Nogueira de Souza - Universidade Estadual do Ceará - Fortaleza - Ceará - Brasil

marcosnogueira@uece.br

\section{Resumo}

A sociedade, ao apropriar-se do território e dos recursos naturais, promove significativas modificações nas paisagens, desencadeando uma série de problemas socioambientais. Nas áreas urbanas essas consequências são mais evidentes, em virtude, principalmente, da ocupação desordenada dos ambientes mais vulneráveis, que gera impactos e riscos emergentes. A pretensão deste texto é apresentar a análise geoambiental como instrumento de investigação da vulnerabilidade e dos riscos ambientais em sistemas marcados pela urbanização. Para tanto, utiliza-se como estudo de caso a bacia hidrográfica do rio Cocó, localizada na Região Metropolitana de Fortaleza (CE). Os resultados obtidos mostram a eficácia da aplicação desse tipo de abordagem para a compreensão da distribuição espacial dos riscos e identificação de territórios mais susceptíveis a esses problemas.

Palavras-chave: análise geoambiental, vulnerabilidade ambiental, ambiente urbano, riscos ambientais.

\begin{abstract}
When society appropriates territory and natural resources, it promotes significant modifications on landscapes culminating in a series of socioenvironmental issues. However, such consequences are more evident in urban areas due to disordered occupation in the most vulnerable environments generating impacts and emergent risks. This work aims to present geoenvironmental analysis as instrument of investigation of vulnerability and environmental risks in systems marked by urbanization. For that, Cocó river watershed, in metropolitan region of Fortaleza, was used as study case. Results showed the efficiency of this type of investigation, making possible to comprehend the spatial distribution of risks and identification of territories more susceptible to these problems. Key words: geoenvironmental analysis, environmental vulnerability, urban environment, environmental risks.
\end{abstract}

\section{Résumé}

En s'appropriant le territoire et les ressources naturelles, la société favorise des changements importants dans les paysages déclenchant une série de problèmes environnementaux. Toutefois, c'est dans les zones urbaines où les conséquences sont plus évidentes, surtout en raison de l'occupation désordonnée des environnements les plus vulnérables, produisant des impacts et des risques émergents. Le but de cet article est de présenter I'analyse géo- environnementale comme outil d'investigation de la vulnérabilité et des risques environnementaux en milieu urbain. Pour ce faire, on utilise comme étude de cas le bassin versant de la rivière Cocó, situé dans la région métropolitainte de Fortaleza. Les résultats montrent l'efficacité de l'application de ce type d'investigation pour comprendre la distribution spatiale des risques et identifier les zones les plus sensibles à ces problèmes.

Mots-clés: analyse géo-environnementale, vulnérabilité de l'environnement, environnement urbain, risques environnementaux. 
Introdução

O século XX foi marcado por expressivo crescimento e adensamento demográfico, com a formação de grandes aglomerados urbanos que introduziram profundas alterações na relação sociedade/natureza. Essas alterações produziram efeitos mais marcantes nos países em desenvolvimento, onde, via de regra, o crescimento demográfico e urbano não foi acompanhado de ações estruturantes capazes de minimizar os efeitos adversos desse processo.

O Brasil adentra efetivamente nesse contexto na segunda metade do século XX. Em 1940, o país era predominantemente rural, com apenas $26 \%$ da população vivendo nas cidades. No ano de 2010 , a população urbana atinge mais de $84 \%$ do contingente total. Esse processo, segundo Maricato (2001), foi desencadeado por forte intervenção estatal pautada no binômio crescimento e pobreza, com a concentração dos investimentos financeiros nos grandes centros urbanos. Ainda segundo a autora, o fim desse suposto desenvolvimento, na década de 1980, ocasionou a ampliação das desigualdades sociais, originando enorme massa de excluídos.

Como consequência direta da urbanização, tem-se a supervalorização do espaço urbano, acentuando a segregação espacial e dificultando o acesso à moradia, fazendo com que a população de baixa renda busque opções de sobrevivência e venha a ocupar terrenos que são constantemente sujeitos às contingências ambientais, configurando as chamadas áreas de risco. Essas áreas, em geral, são constituídas por ambientes legalmente protegidos, onde há precariedade do controle ambiental e, consequentemente, ausência de fiscalização, favorecendo a ocupação (Maricato, 2001). O problema da ocupação de áreas de risco assume proporções alarmantes nas cidades dos países em desenvolvimento, especialmente nos aglomerados latino-americanos (Veyret; Richemond, 2007), realidade que pode ser facilmente verificada na Região Metropolitana de Fortaleza (RMF) e, em especial, na bacia hidrográfica do rio Cocó.

Embora os eventos naturais possam se manifestar indistintamente nos sistemas ambientais, emerge a necessidade de desvendar as condicionantes, naturais e sociais, que explicam a maior evidência dos riscos no meio urbano. Essa maior incidência estaria relacionada à inexistência de espaços destinados a amenizar os efeitos das cheias? A própria dinâmica ambiental favorece a ocorrência de riscos? O elevado adensamento ur- 
bano, associado à ocupação irregular dos ambientes fortemente instáveis, amplia a exposição aos riscos? Para esses questionamentos, não há respostas imediatas. Ao contrário, suscitam a necessidade de se desenvolverem investigações ambientais integradas, de modo que possam ser delimitadas as vulnerabilidades ambientais, para a condução de um adequado ordenamento territorial.

O objetivo deste artigo é apresentar a análise geoambiental como possibilidade de investigação da vulnerabilidade e dos riscos ambientais em áreas que sofrem os efeitos adversos da acelerada urbanização. Para tanto, utiliza-se como estudo de caso a bacia hidrográfica do rio Cocó, localizada na Região Metropolitana de Fortaleza (RMF). A referida bacia compreende um mosaico diversificado de sistemas ambientais que abrigam acentuadas condições de geodiversidade e de biodiversidade. Esses diferentes sistemas, em sua maioria, foram fortemente alterados em decorrência de um processo desordenado de ocupação do território, ensejando impactos e riscos de natureza muito variada.

\section{Vulnerabilidade e riscos em ambientes urbanos}

Os estudos que se direcionam ao entendimento da vulnerabilidade e dos riscos ambientais são complexos e podem assumir diversas perspectivas de investigação. Tal característica faz com que as noções de risco e vulnerabilidade sejam amplamente tratadas nos diversos campos disciplinares (Souza; Zanella, 2009).

Conceitualmente, risco é um termo genérico que pode ser definido em diversas categorias, indo do risco econômico ao ambiental. Vários são os fatores geradores de riscos e podem estar relacionados aos processos naturais e às atividades humanas. Veyret e Richemond (2007) afirmam que, em geral, os diferentes fatores de risco interagem uns com os outros, de forma que alguns pertencem simultaneamente a várias categorias.

Conforme Brilhante (2002), a noção de risco, notadamente o risco ambiental, é comumente confundida com a de impacto ambiental. Embora esses dois eventos estejam intimamente relacionados, há diferenças significativas entre eles. Impacto corresponde a uma interferência num ambiente, podendo ser positiva ou negativa, já o risco está associado à noção de probabilidade e, quando da sua ocorrência, assume sempre um efeito negativo. 
Alves (2000) assinala que o risco é o resultado entre o evento e a vulnerabilidade dos elementos sob o risco, e que corresponde à sua predisposição em ser afetado ou estar susceptível a sofrer perdas - danos -, ou seja, é a vulnerabilidade a que um sistema ou comunidade estão expostos em um dado evento perigoso (hazard), evento este associado a um fenômeno natural agravado ou provocado pelo homem (Santos; Souza, 2006).

Comumente a noção de risco é associada a um perigo imediato. O risco não significa necessariamente uma situação de perigo. Sair de casa representa um risco, já que se pode ser atropelado, assaltado, vítima de uma bala perdida etc. Porém, seria exagerado garantir que o ato de sair de casa corresponda a um perigo. Embora se esteja sujeito a essas situações, não significa que elas estejam na iminência de acontecer. É nesse sentido que a ideia de probabilidade assume seu papel, pois tais eventos têm probabilidade de acontecer, mas não há certeza de que eles venham a se realizar. O que cabe, na realidade, é saber gerenciar (conviver com) esses riscos, de forma a tomar precauções a fim de evitá-los.

O risco não pode ser considerado puramente como contingência. Ele é parte de uma construção social, sendo produzido com suporte na ação da sociedade. As cheias nas planícies de inundação constituem um fenômeno natural. No entanto, em áreas urbanizadas, manifestam-se em forma de catástrofe, pois a busca por espaços, sobretudo os destinados à moradia, é constante. Os elevados índices de impermeabilização reduzem a infiltração e favorecem o aumento da velocidade e intensidade do escoamento superficial, motivando maior aporte de água nos canais fluviais. Dessa forma, estes não apresentam capacidade de dar vazão ao volume de água recebido, o que ocasiona o extravasamento das águas para as áreas marginais. Sobre a intensificação do escoamento superficial decorrente da urbanização, Christofoletti (2001) ressalta que a ampliação das áreas impermeabilizadas favorece a concentração das enxurradas, reduzindo drasticamente o tempo de retorno para ondas de cheias de mesma magnitude.

Nas cidades, quando ocorrem fenômenos naturais simples, como as enchentes, estas se transformam em calamidades, em razão da falta de racionalidade na ocupação e gerenciamento do espaço urbano. A esse respeito, Hétu (2003, p. 87) afirma: 
$\mathrm{Na}$ maioria dos casos, quando um agente natural atinge uma casa ou uma rodovia, trata-se de um problema de localização, a causa primeira da catástrofe e não a fatalidade: as pessoas e/ou a infraestrutura se encontravam em local e momento inadequado. Portanto, e fundamentalmente, é a nossa capacidade de gerenciar bem o espaço que é questionada.

Em um sistema urbano, os riscos ambientais fazem-se presentes de modo mais evidente nas chamadas áreas de risco. Consideram-se áreas de risco os ambientes susceptíveis à ação dos agentes naturais, que põem em risco a vida da população que ali vive, com base em uma relação de causa e efeito. Tem-se como causa mais evidente a ocupação de áreas impróprias, que deveriam ser destinadas à preservação e manutenção da funcionalidade dos sistemas naturais. Como resultado, salienta-se a alteração do funcionamento desses sistemas, expondo, frequentemente, comunidades aos efeitos dos agentes naturais caracterizados pela sazonalidade (Santos; Souza, 2006).

Coelho (2001) ressalta que os problemas ambientais não atingem igualmente todo o espaço urbano. Alcançam muito mais os espaços ocupados por população de baixa renda, que não pode pagar por terrenos mais seguros do ponto de vista ambiental. Ressalta, ainda, que a distribuição espacial dessa população está associada à desvalorização do espaço pela proximidade de áreas inundáveis, de indústrias poluidoras, insalubridade dos terrenos, ou pela ocorrência de riscos ambientais e catástrofes naturais como terremotos e vulcanismos.

No mesmo sentido, Thouret (2007) diz que a segregação social e espacial cria uma exposição desigual aos riscos, realidade que pode ser facilmente verificada nos grandes centros urbanos dos países em desenvolvimento, em especial na América Latina, onde a vulnerabilidade está ligada ao subdesenvolvimento, à má qualidade das construções e ao fraco preparo da sociedade e das esferas governamentais para enfrentar a crise e a urgência.

Evidencia-se, portanto, que a vulnerabilidade é uma categoria de análise multidimensional que ultrapassa uma abordagem meramente probabilística. Veyret e Richemond (2007) ressaltam que a vulnerabilidade não pode ser definida somente em razão de um aspecto; ela é, na verdade, resultado de um complexo jogo de relações que envolve aspectos físicos, ambientais, técnicos, econômicos, sociais, políticos e psicológicos. 
No contexto da análise dos riscos, a vulnerabilidade ambiental pode ser entendida como o grau de exposição a diferentes fatores que podem acarretar efeitos adversos, tais como impactos e riscos, derivados ou não das atividades socioeconômicas.

O estabelecimento das relações entre impactos, riscos, e processo de uso e ocupação do espaço associado às condições socioeconômicas das populações, permite identificar a maior ou menor vulnerabilidade à incidência de riscos ambientais, conforme as respostas do sistema a essas alterações. Dessa forma, fica evidente que, quando da ocorrência de desastres, não se pode atribuir uma causa única a essa ocorrência. Como bem ressalta Brilhante (2002), a ocorrência de desastres envolve uma cadeia de causas e efeitos, em que uma série de eventos individuais são combinados para produzi-los.

É importante destacar que os efeitos negativos da ocupação desordenada não são sentidos igualmente por toda a sociedade. Portanto, a vulnerabilidade está diretamente relacionada às condições socioeconômicas da população, seja numa perspectiva global, ao se analisar a vulnerabilidade dos países em desenvolvimento em face dos mais industrializados, seja numa perspectiva local, considerando-se os diferentes níveis de vulnerabilidade em decorrência da distribuição espacial da população no espaço urbano ou em uma bacia hidrográfica.

A distribuição desigual dos problemas ambientais é decorrente de inúmeros fatores, tais como: condições socioeconômicas, qualidade das construções, disponibilidade de infraestrutura (abrigos subterrâneos, diques marginais para a contenção de cheias, sistemas eficientes de drenagem urbana etc.), sistemas de alerta, capacidade de resposta do governo e dos grupos sociais perante situações de crise, entre tantos outros aspectos que são condicionados e condicionam o uso e a apropriação do território.

Analisar a vulnerabilidade de determinadas áreas, principalmente urbanizadas, em face dos problemas ambientais a que estão susceptíveis, permite identificar os principais riscos que podem ser desencadeados e elaborar estratégias de gerenciamento no intuito de minimizar os prejuízos, materiais e sociais, que podem ocorrer. Para tanto, é necessário o conhecimento das condições geoambientais, possibilitando um diagnóstico que oriente o entendimento das causas e das consequências dos riscos. Esse produto deve subsidiar planos de ações integradas, com estratégias de atuação em situações de crise e planejamento para a redução dos ris- 
cos, sobressaindo um modelo de zoneamento ambiental capaz de definir áreas propícias ou não aos diferentes tipos de ocupação.

\section{Bases conceituais e procedimentos}

A partir da segunda metade do século XX vários autores passaram a discutir abordagens integradas em geografia, estabelecendo avaliações multitemáticas que consideram etapas analíticas, integrativas e sintéticas (Santos; Ross, 2012). As referidas análises partem das relações de interdependência entre os componentes ambientais numa perspectiva de totalidade, constituindo um novo paradigma na análise geográfica.

Embora exista um amplo arcabouço teórico, metodológico e conceitual sobre o desenvolvimento de avaliações ambientais integradas, em sua maioria, estas não são direcionadas ao entendimento da problemática ambiental urbana. Acselrad (1999) destaca que as articulações entre as questões urbanas e ambientais fazem parte das relações que se dão em torno da apropriação do território e de seus recursos. Para o autor, essas práticas, a depender do contexto político, tanto podem promover um processo de melhoria das condições de vida, como podem ampliar os conflitos ambientais e territoriais.

Conforme Lima-e-Silva et al. (2000), para se entenderem as mudanças ocorridas no meio ambiente urbano, faz-se necessário entender a dinâmica dos componentes naturais e suas relações com a estrutura social. Segundo esses autores, as grandes cidades são locais de conflitos de interesses - notadamente entre a classe mais abonada e a camada mais pobre -, pois são objeto de transformações significativas em virtude das mudanças ocorridas no ambiente, em espaços muito reduzidos e adensados demograficamente.

O ambiente urbano é um sistema altamente inter-relacionado, em que tanto os elementos que são obra das atividades humanas como os elementos naturais são parte do sistema de relações, e os resultados, bons ou ruins, são fruto da combinação dos dois (Brandão, 2001). Nesse sentido, emerge a necessidade da utilização de metodologias de investigação que considerem de forma integrada a complexidade das relações da sociedade com a natureza.

A análise geoambiental parte da concepção dos geossistemas, que leva em conta a forma como se organizam e inter-relacionam os diversos 
componentes da paisagem. Tal concepção considera o estudo integrado dos componentes da paisagem, possibilitando compreender o funcionamento e a dinâmica dos ambientes naturais e dos ambientes alterados pelas atividades antropogênicas.

Souza (2000), à luz da teoria ecodinâmica de Tricart (1977), afirma que, com base no potencial de recursos naturais, nas principais limitações de uso e no estado atual de conservação, é possível diagnosticar estágios de vulnerabilidade e sustentabilidade ambiental. Em estudos para o Estado do Ceará, o autor estabeleceu três níveis hierárquicos de sustentabilidade e de categorias de vulnerabilidade: baixa, moderada e alta.

Mediante a análise qualitativa dessas categorias, é possível entender os processos atuantes das principais limitações de uso, do estado atual de conservação e das tendências de evolução dos geoambientes. Essas informações fornecem as condições para o estabelecimento de cenários de tendências futuras e a indicação das principais vulnerabilidades e dos principais riscos a que estão susceptíveis.

A identificação da vulnerabilidade e dos riscos ambientais requer o desenvolvimento de estudos e avaliações multitemáticas que envolvem atividades de campo e escritório, complementares e inter-relacionadas. Essas análises possibilitam a eliminação das barreiras formais entre os temas investigados, privilegiando uma visão sintética da estrutura funcional das relações entre a sociedade e a natureza.

A análise geoambiental é considerada como instrumento de aplicabilidade da teoria dos sistemas. Essa perspectiva considera as relações entre as condições naturais e sociais que configuram diferentes sistemas ambientais. Pressupõe aspectos relacionados aos condicionantes geológico-geomorfológicos, hidroclimatológicos, pedológicos, fitoecológicos e às alterações promovidas pelas atividades antropogênicas (Souza, 2000). A aplicação desse tipo de investigação, em ambientes urbanos, encontra respaldo em diferentes autores, destacando-se os trabalhos de Santos e Souza (2006); Souza et al. (2009) e de Santos e Ross (2012).

Os sistemas ambientais são identificados e hierarquizados conforme a inter-relação dos seus componentes geoambientais, suas dimensões e características de origem e evolução. Considerando a diversidade interna dos sistemas, são delimitadas as unidades elementares contidas em um mesmo sistema de relações que configura, espacialmente, os subsistemas. Sob esse aspecto, a concepção de paisagem assume significado 
para a delimitação das subunidades, em decorrência da exposição de padrões fisionômicos uniformes ou de relativa homogeneidade.

Inicialmente são realizados estudos de base físico-ambientais, com base em proposta geossistêmica, para o delineamento da compartimentação dos sistemas ambientais. As contradições da sociedade dividida em classes são apresentadas nos padrões de uso e ocupação, que compreendem a materialização espacial das relações da sociedade no território. A incorporação dos conceitos e princípios da ecodinâmica, associados às avaliações anteriormente procedidas, permite definir o grau de vulnerabilidade dos sistemas perante o desenvolvimento das atividades produtivas e culturais.

Mediante esses preceitos, faz-se possível o estabelecimento de sistemática operacional abrangendo três fases fundamentais: analítica, sintética e integrativa (Souza, 2000). A fase analítica compreende a coleta, o armazenamento e o tratamento dos dados geoambientais e suas inter-relações. A síntese consiste na seleção e associação dos parâmetros identificados na fase anterior. Nessa etapa, são consideradas as relações sociais espacializadas no território através dos diferentes tipos de uso e ocupação. Por fim, na terceira etapa (integrativa), são associados os parâmetros relativos às condições ambientais e socioeconômicas de forma sistêmica e holística, resultando na delimitação da vulnerabilidade ambiental e identificação das áreas de risco.

A partir dos procedimentos relacionados, com base em Souza (2000), é possível delimitar os graus de vulnerabilidade e sustentabilidade dos sistemas ambientais. A vulnerabilidade constitui o referencial básico para a definição das unidades de intervenção, classificadas em: medianamente estáveis, medianamente frágeis e frágeis. Essas unidades expressam as limitações impostas ao uso e à ocupação, constituindo importante subsídio ao ordenamento territorial.

Vulnerabilidade, impactos e riscos na bacia hidrográfica do rio Cocó

A bacia hidrográfica do rio Cocó está inserida totalmente na Região Metropolitana de Fortaleza (RMF), sendo o Cocó o principal rio da cidade de Fortaleza. Suas nascentes estão localizadas na vertente oriental da Serra da Aratanha, município de Pacatuba, com coordenadas de $38^{\circ} 35^{\prime}$ de longitude oeste e $4^{\circ}$ de latitude sul, indo desaguar no Oceano Atlântico, na praia do Caça e Pesca em Fortaleza (Figura 1). A área total de drenagem da bacia 
é de aproximadamente 513,84 $\mathrm{km}^{2}$, abrangendo parte dos municípios de Pacatuba, Maranguape, Itaitinga, Maracanaú, Eusébio, Aquiraz e Fortaleza.

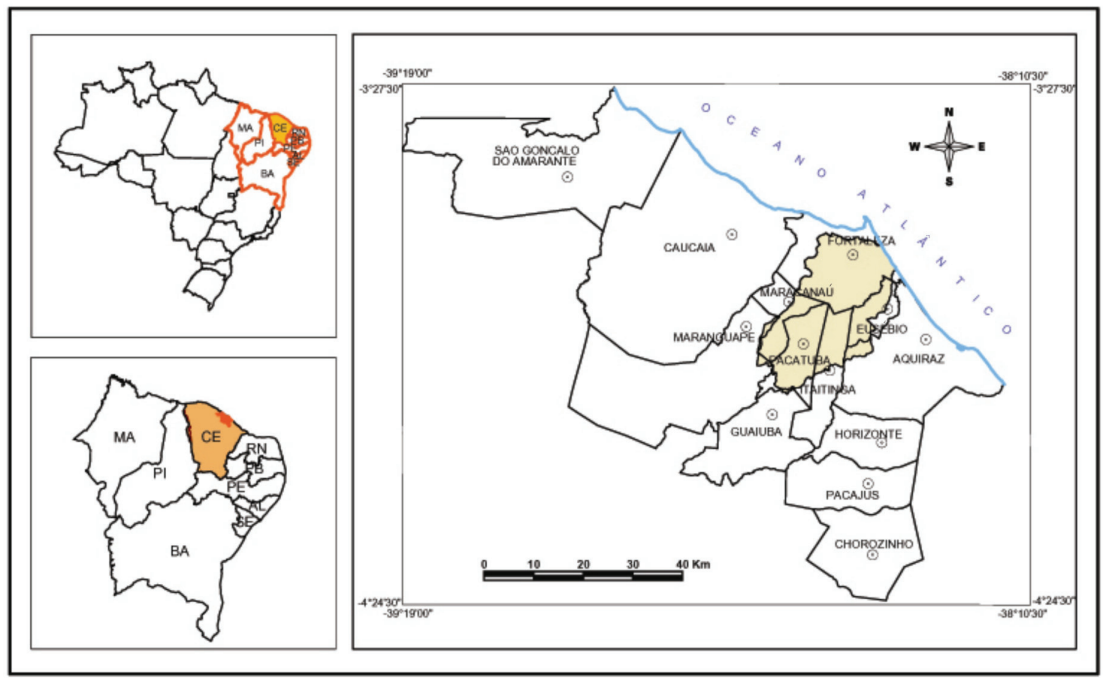

Figura 1 - Localização da bacia hidrográfica do rio Cocó.

Na área de drenagem da bacia hidrográfica do rio Cocó, verifica-se a ocorrência de dois principais grupos litológicos, expressos pelos terrenos cristalinos e pelas coberturas sedimentares Cenozoicas (Brandão, 1995; Brandão et al., 1995; Souza, 2000).

Os terrenos cristalinos são compostos de rochas do Complexo Nordestino e configuram os maciços residuais e a depressão sertaneja. As coberturas sedimentares Cenozoicas são compostas por sedimentos de origem continental e marinha, tendo como principais unidades os tabuleiros pré-litorâneos da Formação Barreiras e os sedimentos arenoquartzosos da planície litorânea (faixa praial, campo de dunas móveis e fixas e planície fluviomarinha) e planície fluvial. O Morro Caruru e a Crista do Ancuri são relevos residuais esculpidos em rochas vulcânicas alcalinas associadas ao vulcanismo Terciário.

Assim como ocorre na maior parte do Nordeste setentrional, as chuvas na bacia concentram-se em cerca de $90 \%$ no primeiro semestre do ano, tendo seu ápice nos meses de março a maio. A Zona de Convergência Intertropical (ZCIT) é o principal sistema responsável pelo esta- 
belecimento da quadra chuvosa. Ela se faz mais evidente quando da sua máxima aproximação no Hemisfério Sul, durante o equinócio outonal (23 de março), retornando ao Hemisfério Norte no mês de maio, ocasionando o declínio do período chuvoso (Souza et al., 2009).

Os solos constatados na bacia têm variações significativas quanto à tipologia, classes e variação espacial. Verifica-se, contudo, estreita relação entre as classes de solos e o contexto geomorfológico. No que se refere aos aspectos fitoecológicos, pode-se constatar um avançado estágio de degradação da vegetação primária, com espécies de porte predominantemente arbustivo.

Considerando as relações de interdependência entre os componentes ambientais e seguindo os delineamentos de Souza (2000), Santos e Souza (2006), Souza et al. (2009), Santos (2011) e de Santos e Ross (2012), foi definida a compartimentação geoambiental, que estabelece a hierarquização dos sistemas e subsistemas ambientais, representados de forma sintética na Figura 2.

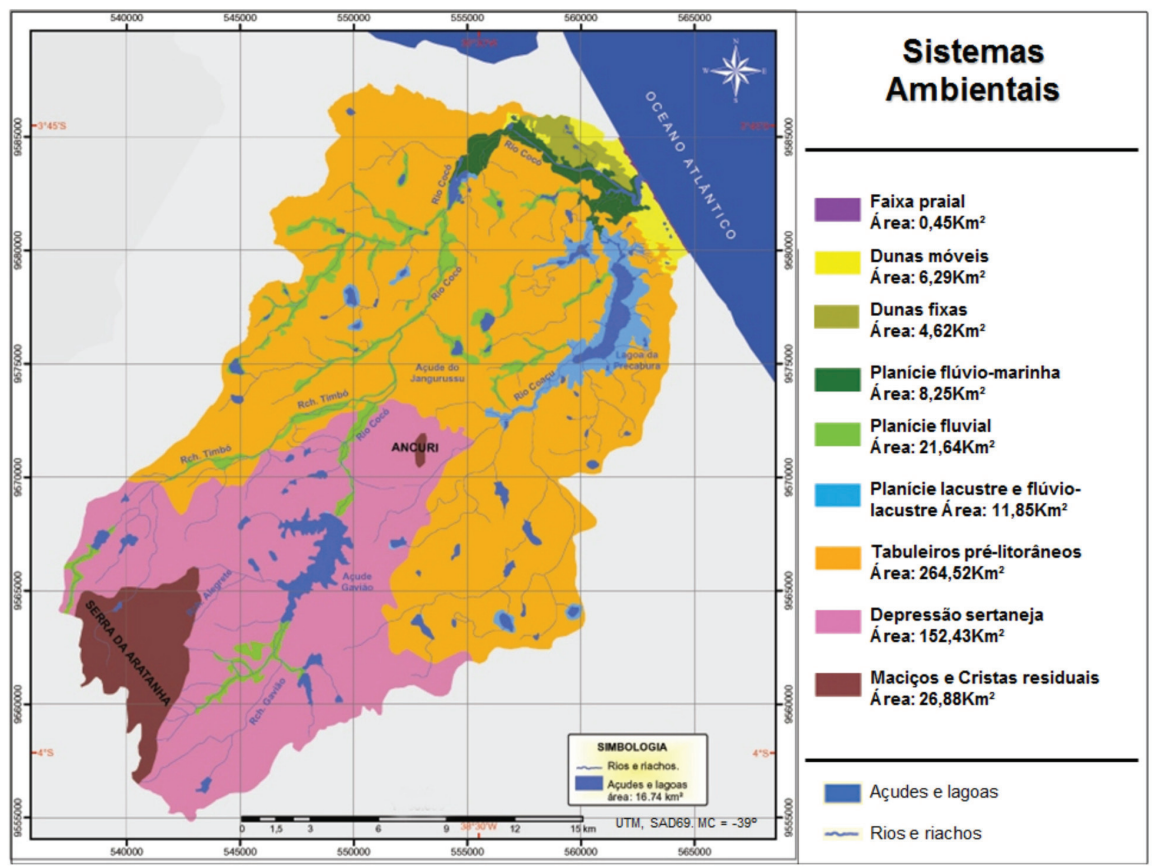

Figura 2 - Sistemas ambientais na bacia hidrográfica do rio Cocó. 
Ocupação, impactos e riscos

As formas de uso e ocupação da terra derivam das atividades socioeconômicas e, por conseguinte, refletem o desenvolvimento do sistema técnico-científico e as relações estabelecidas entre sociedade e natureza, denunciando o grau de conservação, preservação e degradação dos recursos naturais em face dos processos produtivos.

Os contrastes sociais existentes garantem a heterogeneidade e coexistência de variadas formas de uso e ocupação da terra que denunciam o emprego de diferentes estágios de desenvolvimento técnico, com a presença de atividades sofisticadas que empregam alta tecnologia e outras que utilizam tecnologia extremamente rudimentar. A Figura 3 sintetiza as principais formas de uso e ocupação na bacia do rio Cocó.

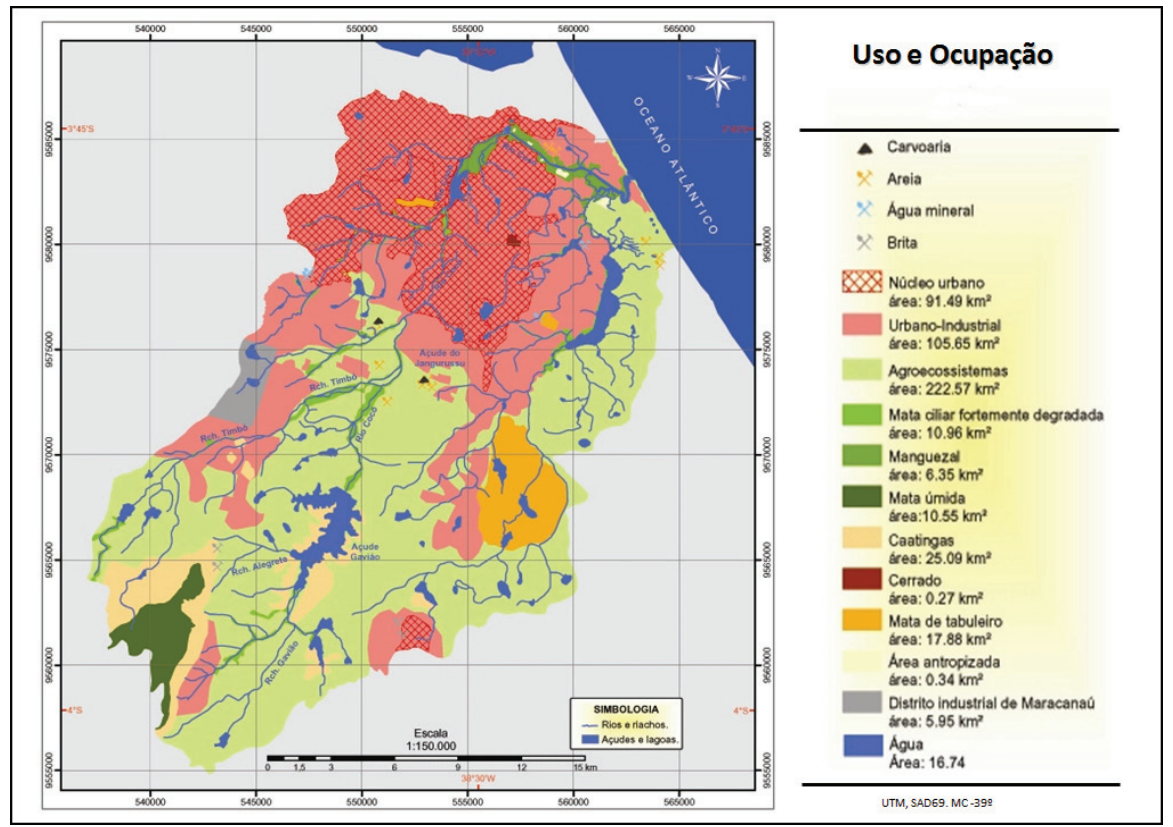

Figura 3 - Principais formas de uso e ocupação na bacia do rio Cocó.

Os sistemas ambientais existentes nessa bacia apresentam diferentes estágios de vulnerabilidade, impactos e riscos. Apesar de a porção mais densamente ocupada estar situada primordialmente sobre os ter- 
renos medianamente estáveis dos tabuleiros pré-litorâneos, verifica-se a ocorrência frequente dos efeitos de eventos catastróficos, sobretudo nos ambientes Quaternários das planícies fluviais e litorânea. A falta de infraestrutura para o enfrentamento de situações de crise e catástrofes acentua ainda mais os problemas.

A incidência de cheias e inundações, nas áreas de risco do rio Cocó, motiva uma série de danos diretos e indiretos às comunidades que residem nesses locais. Esses danos estão relacionados à integridade física das pessoas e às perdas materiais e patrimoniais. Os danos diretos relacionam-se a mortes, destruição de moradias, perdas econômicas e gastos com recuperação. Já os indiretos podem ser sentidos por meio da mobilidade da população, perda da identidade e dos laços de vizinhança, e pela incidência de riscos epidemiológicos com surtos de doenças transmissíveis pela água.

Embora existam algumas áreas de risco dispersas ao longo de toda a bacia, o presente artigo traz a análise das áreas de risco na cidade de Fortaleza, com base nos dados referentes ao período compreendido entre 1999 e 2007. Tal escolha decorre da disponibilidade de dados oficiais sobre essas áreas.

Em 1999, havia 45 áreas de risco em Fortaleza, totalizando uma população de 21.435 pessoas ali residentes (CPDH, 1999). Em 2007, essas aglomerações somavam 105 áreas de risco, com 22.984 famílias, totalizando 96.532 moradores (COMDECFor, 2007), o que configura um crescimento superior a $536 \%$.

Das 105 áreas de risco existentes, em 2007, na capital cearense, 37 se encontravam na bacia do rio Cocó (Figura 4), o que representa cerca de $38,85 \%$ do total, com 8.860 famílias expostas aos riscos. A maioria dessas áreas está relacionada aos problemas de enchentes e inundações: 36 áreas, abrigando 8.588 famílias, equivalentes a cerca de 36.070 pessoas.

A maior concentração ocorre no médio-baixo curso do Cocó, nas Áreas de Preservação Permanente e planícies de inundação que bordejam a calha principal do rio. As áreas retrocitadas são consideradas de alto risco, já que é frequente a ocorrência de enchentes e inundações em, pelo menos, três vezes num período de cinco anos (Santos, 2006), ou seja, o tempo de retorno é muito curto e a frequência bastante elevada. 


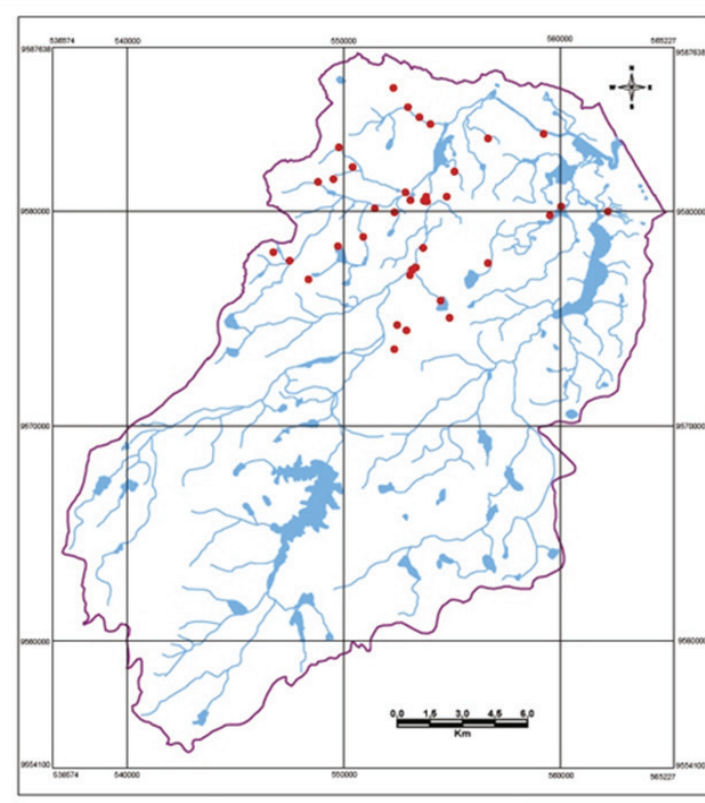

\section{Áreas de Risco na Bacia Hidrográfica do Rio Cocó}

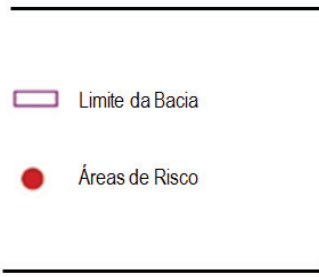

Açudes e lagoas

- Rios e riachos

UTM, SAD69. MC-399

Figura 4 - Áreas de risco na bacia do rio Cocó, em Fortaleza (CE).

Subsídios ao planejamento territorial: unidades de intervenção

A definição da vulnerabilidade ambiental partiu da análise das potencialidades e limitações naturais dos sistemas ambientais, associadas às condicionantes socioeconômicas, representadas pelas formas de uso e ocupação do território. Foram definidas estas três categorias de unidades de intervenção: áreas frágeis, áreas medianamente frágeis e áreas medianamente estáveis (Figura 5).

Áreas frágeis são constituídas por ambientes fortemente instáveis e que, por conseguinte, apresentam vulnerabilidade elevada. A definição dessas áreas considera, também, as limitações impostas pela legislação ambiental, notadamente as Áreas de Preservação Permanente e Unidades de Conservação.

Áreas medianamente frágeis são compostas pelas áreas que apresentam frágil equilíbrio entre as condições de morfogênese e pedogênese, configurando ambientes de vulnerabilidade moderada. Esses ambientes 
podem ser influenciados pelas atividades socioeconômicas e, por isso mesmo, requerem critérios específicos de uso e ocupação do solo para que o equilíbrio ambiental não seja alterado.

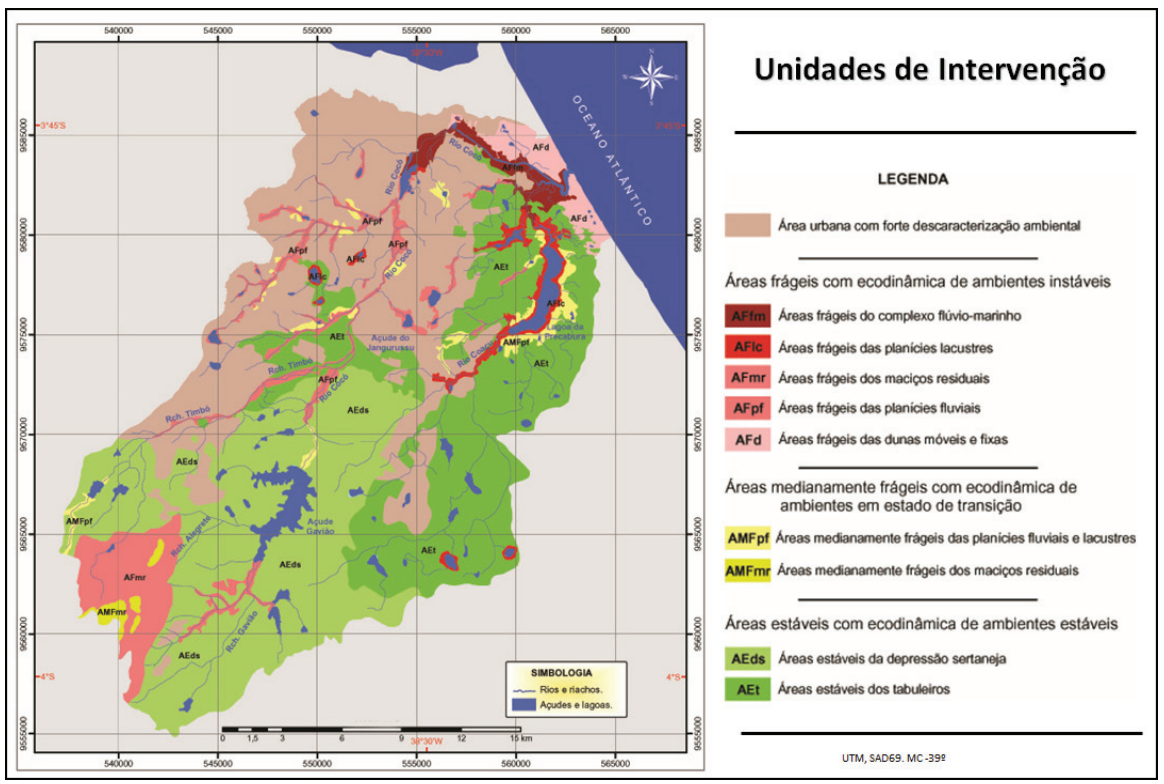

Figura 5 - Unidades de intervenção.

Áreas medianamente estáveis são representadas pelos ambientes que apresentam baixa vulnerabilidade ao estabelecimento das atividades produtivas. São ambientes, via de regra, mais antigos, onde a estabilidade morfogenética é mais evidente. Essas áreas, em geral, não apresentam maiores problemas para a expansão urbana e para o desenvolvimento de atividades agrícolas, desde que sejam utilizadas técnicas não predatórias.

O Quadro 1 sintetiza a vulnerabilidade dos ambientes associando o sistema ambiental incidente e as diretrizes ambientais para o ordenamento territorial. 
Quadro 1 - Vulnerabilidade ambiental na bacia do rio Cocó.

\begin{tabular}{|c|c|c|}
\hline $\begin{array}{l}\text { Vulnerabilidade } \\
\text { do ambiente }\end{array}$ & Sistemas Ambientais & Diretrizes Ambientais \\
\hline \multirow{5}{*}{$\begin{array}{l}\text { Áreas Frágeis } \\
-\mathbf{A F}\end{array}$} & AFfm - Complexo fluviomarinho & \multirow{5}{*}{$\begin{array}{l}\text { Obediência à legislação ambiental; } \\
\text { recuperação da vegetação primária; } \\
\text { inibição de novas ocupações; } \\
\text { reassentamento das populações; } \\
\text { turismo ecológico; gestão e manejo } \\
\text { das unidades de conservação; } \\
\text { monitoramento da qualidade das águas; } \\
\text { manutenção do patrimônio paisagístico } \\
\text { e da biodiversidade. }\end{array}$} \\
\hline & AFlc-Planícies lacustres & \\
\hline & AFmr - Morros e cristas residuais & \\
\hline & AFpf - Planícies fluviais e fluviolacustres & \\
\hline & AFd - Dunas móveis e fixas & \\
\hline \multirow[b]{2}{*}{$\begin{array}{l}\text { Áreas } \\
\text { Medianamente } \\
\text { Frágeis - AMF }\end{array}$} & AMFpf - Planícies fluviais e lacustres & \multirow{2}{*}{$\begin{array}{l}\text { Ações de manejo; obediência à } \\
\text { legislação ambiental; turismo ecológico } \\
\text { recuperação da vegetação primária; } \\
\text { definição de critérios de uso e } \\
\text { ocupação. }\end{array}$} \\
\hline & AMFmr - Maciços residuais & \\
\hline \multirow[b]{2}{*}{$\begin{array}{l}\text { Áreas } \\
\text { Medianamente } \\
\text { Estáveis - AME }\end{array}$} & AMEds - Depressão sertaneja & \multirow{2}{*}{$\begin{array}{l}\text { Expansão urbana e viária; regulação } \\
\text { do uso e ocupação; manutenção } \\
\text { da capacidade de infiltração; } \\
\text { amortecimento de cheias; criação de } \\
\text { unidades de conservação nas áreas } \\
\text { cobertas por vegetação primária. }\end{array}$} \\
\hline & AMEt - Tabuleiros pré-litorâneos & \\
\hline
\end{tabular}

\section{Considerações finais}

Os resultados obtidos evidenciam que a utilização da análise geoambiental como instrumento de investigação permite enfrentar a complexidade que as investigações relacionadas à vulnerabilidade e aos riscos ambientais requerem.

Observou-se que, embora os eventos comandados pela dinâmica natural possam se manifestar indistintamente nos sistemas ambientais, os riscos se tornam mais evidentes nas áreas urbanizadas. A referida exposição é decorrente da inexistência de espaços que sirvam para amenizar os efeitos das cheias dos canais fluviais, do elevado adensamento demográfico e, principalmente, os efeitos da ocupação irregular dos ambientes fortemente instáveis. Com a investigação conduzida na bacia hidrográfica do rio Cocó, mostrou-se que a análise geoambiental permite identificar territórios com diferentes níveis de vulnerabilidade e exposição aos riscos ambientais.

Mediante o entendimento das relações entre impactos, riscos, uso e ocupação do solo, associados às condições socioeconômicas dos grupos sociais envolvidos, torna-se possível a elaboração de diretrizes que conduzam a um processo de (re)ordenamento do território, visando à redução da incidência de riscos ambientais. 


\section{Referências}

ACSELRAD, H. Discursos da sustentabilidade urbana. Revista Brasileira de Estudos Urbanos e Regionais, Campinas, v. 1, n. 1, p. 79-90, maio 1999.

ALVES, I. C. Perspectiva socioambiental na Vila Santa Isabel, Viamão (RS): estudo de caso. In: SUERTEGARAY, D. M. A.; BASSO, L. A.; VERDUM, R. (Orgs.). Ambiente e lugar no urbano: a grande Porto Alegre. Porto Alegre: Ed. UFRGS, 2000. p. 135-159.

BRANDÃO, A. M. P. M. Clima urbano e enchentes na cidade do Rio de Janeiro. In: GUERRA, A. J. T.; CUNHA, S. B. da (Orgs.). Impactos ambientais urbanos no Brasil. Rio de Janeiro: Bertrand Brasil, 2001. p. 47-109.

BRANDÃO, R. L. Sistema de informações para gestão e administração territorial da Região Metropolitana de Fortaleza - Projeto SINFOR: mapa geológico da Região Metropolitana de Fortaleza. Texto explicativo. Fortaleza: CPRM, 1995. 34 p.

BRANDÃO, R. L.; SOUZA, M. J. N. de; CAVALCANTE, I. N. Diagnóstico geoambiental e os principais problemas de ocupação do meio físico da Região Metropolitana de Fortaleza. Fortaleza: CPRM, 1995. 95 p.

BRILHANTE, O. M. Gestão e avaliação da poluição, impacto e risco na saúde ambiental. In: BRILHANTE, O. M.; CALDAS, L. Q. A. (Coords.). Gestão e avaliação de risco em saúde ambiental. Rio de Janeiro: Fiocruz, 2002. p. 19-73.

CHRISTOFOLETTI, A. Aplicabilidade do conhecimento geomorfológico nos projetos de planejamento. In: GUERRA, A. J. T.; CUNHA, S. B. da (Orgs.). Geomorfologia: uma atualização de bases e conceitos. 4. ed. Rio de Janeiro: Bertrand Brasil, 2001. p. 415-441.

COELHO, M. C. N. Impactos ambientais em áreas urbanas - teorias, conceitos e métodos de pesquisa. In: GUERRA, A. J. T.; CUNHA, S. B. da (Orgs.). Impactos ambientais urbanos no Brasil. Rio de Janeiro: Bertrand Brasil, 2001. p. 19-45.

COMDECFor. Coordenadoria Municipal de Defesa Civil de Fortaleza. Operação inverno: relatório das áreas de risco. Fortaleza, 2007.

CPDH. Centro de Defesa e Promoção dos Direitos Humanos. Perfil socioeconômico das áreas de risco em Fortaleza. Fortaleza, 1999.

HÉTU, B. Uma geomorfologia socialmente útil: os riscos naturais em evidência. Mercator - Revista de Geografia da UFC, Fortaleza, n. 3, p. 83-97, 2003.

LIMA-E-SILVA, P. P.; GUERRA, A. J. T.; DUTRA, L. E. D. Subsídios para avaliação econômica de impactos ambientais. In: GUERRA, A. J. T.; CUNHA, S. B. da (Orgs.). Avaliação e perícia ambiental. 2. ed. Rio de Janeiro: Bertrand Brasil, 2000. p. 217-260.

MARICATO, E. Brasil, cidades: alternativas para a crise urbana. 2. ed. Petrópolis: Vozes, 2001. 204 p.

SANTOS, J. de O. Vulnerabilidade ambiental e áreas de risco na bacia hidrográfica do rio Cocó: Região Metropolitana de Fortaleza (CE). 216f. Dissertação (Mestrado em Geografia) - Universidade Estadual do Ceará, Fortaleza, 2006. 
. Fragilidade e riscos socioambientais em Fortaleza (CE): contribuições ao ordenamento territorial. 315f. Tese (Doutorado em Geografia Física) - Universidade de São Paulo, São Paulo, 2011.

SANTOS, J. de O.; ROSS, J. L. S. Fragilidade ambiental urbana. Revista da ANPEGE, v. 8, n. 10, p. 127-144, 2012.

SANTOS, J. de O.; SOUZA, M. J. N. de. Compartimentação geoambiental e riscos ambientais associados na bacia hidrográfica do rio Cocó, Ceará. In: PINHEIRO, D. R. C. (Org.). Desenvolvimento sustentável: desafios e discussões. Fortaleza: ABC Editora, 2006. p. 75-98.

SOUZA, L. B.; ZANELLA, M. E. Percepção de riscos ambientais: teoria e aplicações. Fortaleza: Ed. UFC, 2009. 240p.

SOUZA, M. J. N. de. Bases naturais e esboço do zoneamento geoambiental do estado do Ceará. In: SOUZA, M. J. N. de; MORAES, J. O.; LIMA, L. C. (Org.). Compartimentação territorial e gestão regional do Ceará. Fortaleza: Ed. FUNECE, 2000. p. 13-98.

SOUZA, M. J. N. de; MENELEU NETO, J.; SANTOS, J. de O.; GONDIM, M. S. Diagnóstico geoambiental do município de Fortaleza: subsídios ao macrozoneamento ambiental e à revisão do Plano Diretor Participativo (PDPFor). Fortaleza: Prefeitura Municipal de Fortaleza, 2009. 172p.

THOURET, J. C. Avaliação, prevenção e gestão dos riscos naturais nas cidades da América Latina. In: VEYRET, Y. (Org.). Os riscos: o homem como agressor e vítima do meio ambiente. São Paulo: Contexto, 2007. p. 83-95.

TRICART, J. Ecodinâmica. Rio de Janeiro: IBGE/SUPREN, 1977. 97 p.

VEYRET, Y.; RICHEMOND, N. M. Definições e vulnerabilidades do risco. In: VEYRET, Y. (Org.). Os riscos: o homem como agressor e vítima do meio ambiente. São Paulo: Contexto, 2007. p. 25-46.

Jader de Oliveira Santos - Graduado em Geografia pela Universidade Federal do Ceará, Mestre em Geografia pela Universidade Estadual do Ceará, Doutor em Geografia pela Universidade de São Paulo, Professor da Universidade Federal do Ceará.

Marcos José Nogueira de Souza - Graduado em Geografia pela Universidade Federal do Ceará, Mestre e Doutor em Geografia pela Universidade de São Paulo, Professor titular aposentado da Universidade Federal do Ceará e Universidade Estadual do Ceará, Professor colaborador do Programa de Pós-Graduação em Geografia da Universidade Estadual do Ceará. 